\title{
Micropropagación in vitro de naranja agria (Citrus aurantium L.) a partir de segmentos nodales
}

\author{
In vitro micropropagation of sour orange (Citrus aurantium L.) from nodal segments
}

Angel David Hernández-Amasifuen, Alexandra Jherina Pineda-Lázaro*, Hermila Belba Díaz-Pillasca

DOI. 10.21931/RB/2021.06.04.13

Resumen: La naranja agria (Citrus aurantium L.) presenta un alto valor nutricional y gastronómico en el distrito de Huacho, Lima, Perú, pero en la actualidad se considera una especie en peligro de desaparecer del distrito y alrededores por problemas fitosanitarios. Para la recuperación y repoblación de esta especie se planteó emplear técnicas biotecnológicas para la obtención de plantas libres de patógenos. Por lo tanto, el objetivo de la presente investigación fue micropropagar in vitro naranja agria a partir de segmentos nodales. Los segmentos nodales de naranja agria fueron desinfectados en diferentes concentraciones de NaClO, luego se introdijeron en medio de cultivo MS (Murashige y Skoog) adicionado con BAP, KIN y AG3 para la fase de multiplicación, posteriormente se transfirieron a medios MS adicionado con IBA y ANA para la fase de enraizamiento. La evaluación del porcentaje de contaminación se realizó a los diez días, la evaluación de formación de brotes en fase de multiplicación se realizó a los 30 días y la evaluación de enraizamiento a los 30 días. En la fase de desinfección y establecimiento in vitro se logró obtener 0\% de contaminación y 0\% de oxidación de los explantes. En la fase de multiplicación in vitro los mejores resultados se obtuvieron en el medio de cultivo M8 generando 4,7 brotes por explante. Y finalmente en la fase de enraizamiento el medio E4 permitió obtener 94,7\% de explantes enraizados, 23,4 mm de longitud de raíz y 2,2 raíces por explante.

Palabras clave: Desinfección, establecimiento, multiplicación, biotecnología, Huacho.

Abstract: Sour orange (Citrus aurantium L.) has a high nutritional and gastronomic value in Huacho, Lima, Peru, but is currently considered a species in danger of disappearing from the district and surrounding areas due to phytosanitary problems. For the recovery and repopulation of this species, biotechnological techniques were proposed to obtain pathogen-free plants. Therefore, the objective of the present research was to micro propagate sour orange in vitro from nodal segments. Sour orange nodal segments were disinfected in different concentrations of $\mathrm{NaClO}$, then placed in MS culture medium (Murashige and Skoog) supplemented with BAP, KIN, and AG3 for the multiplication phase, and then transferred to MS medium supplemented with IBA and ANA for the rooting phase. The evaluation of the percentage of contamination was carried out after 10 days, the evaluation of shoot formation in the multiplication phase was carried out after 30 days, and the evaluation of rooting after 30 days. In the disinfection and in vitro establishment phase, $0 \%$ contamination and $0 \%$ oxidation of the explants were obtained. In the in vitro multiplication phase, the best results were obtained in the M8 culture medium, generating 4.7 shoots per explant. Finally, the E4 medium yielded $94.7 \%$ of rooted explants, $23.4 \mathrm{~mm}$ root length, and 2.2 roots per explant.

Key words: Disinfection, establishment, multiplication, biotechnology, Huacho.

\section{Introducción}

Los cítricos (Citrus) son un importante género de árboles frutales por presentar un alto valor nutricional y económico, encontrándose ampliamente distribuido por todo el mundo debido a su gran consumo ${ }^{1,2}$. Con una producción de 124 millones de toneladas en promedio anualmente a nivel mundial, mientras que en Perú solo se llega a producir un millón de toneladas, de los cuales alrededor del $40 \%$ es producido por naranjas ${ }^{3,4}$.

Dentro de las naranjas que produce el país se tiene a la naranja agria o amarga (Citrus aurantium L.), la cual es utilizada en la gastronomía, como saborizante, en la medicina natural y como portainjerto de gran número de especies de valor comercial, por presentar resistencia a condiciones abióticas como salinidad y sequía, además de ser tolerante a fitopatógenos como Armillaria mellea y Phitophthora sp. ${ }^{5}$. Es así como se puede encontrar a la naranja agria dentro de la biodiversidad vegetal del distrito de Huacho, Provincia de Huaura, Departamento de Lima. La cual es utilizada como insumo para muchos platos típicos de la zona como el ceviche de pato y ceviche de pescado, pero actualmente su producción es esca- sa, al punto de encontrar números reducidos de estos árboles frutales por lo que esta próxima de desaparecer del distrito y sus alrededores ${ }^{6,7}$, esto debido a ser susceptible al virus de la tristeza de los cítricos (CTV), ocasionando escasa longevidad de las plantas, bajos rendimientos y deficiencias de calidad de la fruta ${ }^{8,9}$, y además la preferencia de los agricultores locales a otros cultivos de mayor demanda económica10,11.

Considerando a la naranja agria como una planta de gran importancia gastronómica a nivel local y nacional, se busca estrategias para la recuperación y repoblación de esta especie. En la actualidad se pueden aplicar herramientas de biotecnología vegetal, como el cultivo in vitro de tejidos vegetales ${ }^{12,13}$. Resultando en clones uniformes a partir de una planta madre libre de enfermedades y de gran producción, conservando y garantizando los rasgos seleccionados ${ }^{14}$. Además, la propagación in vitro permite obtener material vegetal durante todo el año, de esta manera no habría un limitante como el suministro de semilla o plantines de invernaderos ${ }^{15,16}$. 
En tal sentido las aplicaciones de los cultivos in vitro no solo se limitan a las altas tasas de multiplicación como método de propagación asexual para la producción de plantas clonales, sino que también forma la base para gran variedad de estudios en la mejora genética vegetal ${ }^{17}$. Es así como se han reportado investigaciones en el cultivo in vitro de cítricos, donde se ha evaluado las diferentes respuestas morfogenéticas influenciadas por la especie, tipo de explante y la composición del medio de cultivo ${ }^{18,19}$. Iniciando desde el establecimiento in vitro de semillas de naranja dulce (Citrus sinensis L.) y su posterior multiplicación a partir de segmentos maduros del tallo²0. De la misma manera ${ }^{21}$, trabajaron inicialmente con semillas de naranja agria y lima (Citrus aurantifolia) respectivamente, para luego multiplicar a las plántulas germinadas empleando diferentes concentraciones de reguladores de crecimiento ${ }^{22}$, trabajo con semillas de naranja y con varetas de limón, logrando establecer in vitro a ambas especies para realizar microinjertos, evaluando la influencia de las concentraciones de sacarosa en el medio de cultivo ${ }^{23}$, realizaron experiencias con yemas de limón criollo (Citrus limon), para la formación de callos y brotes empleando picloram y ácido 2,4-diclorofenoxiacético (2,4-D) $)^{24}$, trabajaron en la micropropagación de limón a partir de segmentos nodales ${ }^{25}$, evaluó el efecto de las citoquininas 6-Bencilaminopurina (BAP) y kinetina (KIN) en la propagación in vitro de lima (Citrus aurantifolia) a partir de segmentos nodales. 26, establecieron un protocolo de micropropagación de citrumelo "Swingle" a partir de segmentos nodales, y lograron obtener tasas aceptables de multiplicación ${ }^{27}$, evaluaron varias concentraciones de reguladores de crecimiento (citoquininas, auxinas y ácido giberélico) en el medio de cultivo MS para inducir la formación de brotes a partir de segmentos nodales de naranja agria y mandarina.

Por lo tanto, el objetivo del presente estudio fue lograr la micropropagación in vitro de naranja agria a partir de segmentos nodales, estableciendo un protocolo óptimo de propagación efectiva para la obtención de una fuente ideal de material aséptico y homogéneo para usar en programas de mejoramiento genético vegetal.

\section{Materiales y métodos}

La investigación se realizó en el Laboratorio de Biotecnología Vegetal de la Escuela Profesional de Biología con mención en Biotecnología, Facultad de Ciencias, Universidad Na- cional José Faustino Sánchez Carrión, en el distrito de Huacho, provincia de Huaura, departamento de Lima, Perú.

\section{Material vegetal}

Se emplearon segmentos nodales de naranja agria procedentes del vivero que pertenece al Laboratorio de Biotecnología Vegetal, ubicada en la ciudad universitaria de la Universidad Nacional José Faustino Sánchez Carrión; situado a una altitud de $41 \mathrm{msnm}$, latitud sur $11^{\circ} 7^{\prime} 34^{\prime \prime}$ y longitud oeste $77^{\circ}$ 36 ' $34^{\prime \prime}$, con temperatura media anual de $19,2^{\circ} \mathrm{C}$.

\section{Desinfección y establecimiento in vitro de segmentos nodales}

Los segmentos nodales fueron llevados a laboratorio donde se lavaron con agua destilada durante 5 minutos y se continuo se inició con el proceso de desinfección. Se trasladaron a cámara de flujo laminar y se sumergieron en etanol al $70 \%$ durante 1 minuto, después fueron sumergidos durante 5 minutos en solución de hipoclorito de sodio ( $\mathrm{NaClO}$ ) al 1\%, seguido se sometieron a cuatro tratamientos con variaciones en las concentraciones de hipoclorito de sodio: 1\% (T1), 1,5\% (T2), 2\% (T3) y 2,5\% (T4) durante 10 minutos cada uno en agitación continua y luego se realizaron tres enjuagues en agua destilada estéril para eliminar los residuos de hipoclorito de sodio, seguido los segmentos nodales se cortaron por la parte inferior y superior hasta tener un explante de aproximadamente $1.5 \mathrm{~cm}$ de longitud. Finalmente fueron introducidos in vitro en tubos con medio de cultivo $\mathrm{MS}^{26}$ a la mitad de su concentración, adicionado con $6 \mathrm{~g} / \mathrm{L}$ de agar, $15 \mathrm{~g} / \mathrm{L}$ de sacarosa y $\mathrm{pH}$ a 5,7 . El medio de cultivo empleado fue previamente esterilizado en autoclave a 1,2 Bar de presión y una temperatura de $121^{\circ} \mathrm{C}$ durante 20 minutos.

\section{Multiplicación in vitro}

A los 30 días se realizaron cortes para obtener nuevamente segmentos nodales, los cuales fueron cultivados in vitro en el medio de cultivo MS suplementado con reguladores de crecimiento en diferentes tratamientos (Tabla 1). El medio de cultivo fue preparado con sales y vitaminas del medio de cultivo MS adicionado con $7 \mathrm{~g} / \mathrm{L}$ de agar, $23 \mathrm{~g} / \mathrm{L}$ de sacarosa y se ajustó el pH a 5,7. El medio de cultivo fue dispensado en 10 $\mathrm{mL}$ por frasco y luego se sellaron con papel aluminio y fueron esterilizados en autoclave a 1,2 Bar de presión y una temperatura de $121^{\circ} \mathrm{C}$ durante 20 minutos.

\begin{tabular}{|c|c|c|c|}
\hline Tratamiento & KIN (mg/L) & BAP (mg/L) & AG $\mathbf{3}(\mathbf{m g} / \mathbf{L})$ \\
\hline M1 & 0 & 0 & 0 \\
\hline M2 & 0,25 & 0 & 0 \\
\hline M3 & 0 & 0,25 & 0 \\
\hline M4 & 0 & 0 & 0,25 \\
\hline M5 & 0,25 & 0,25 & 0 \\
\hline M6 & 0,25 & 0 & 0,25 \\
\hline M7 & 0 & 0,25 & 0,25 \\
\hline M8 & 0,25 & 0,25 & 0,25 \\
\hline
\end{tabular}

Tabla 1. Combinación de los reguladores de crecimiento en el establecimiento in vitro de naranja agria (Citrus aurantium L.).

$\mathrm{KIN}=$ Kinetina; $\mathrm{BAP}=$ 6-Bencilaminopurina; $\mathrm{AG}_{3}=$ Ácido Giberélico . 


\section{Enraizamiento in vitro}

Transcurrido 30 días los explantes fueron transferidos a frascos que contenían medio de cultivo MS suplementado con auxinas en distintos tratamientos (Tabla 2). El medio de cultivo fue preparado con las sales y vitaminas del medio de cultivo MS adicionado con $7 \mathrm{~g} / \mathrm{L}$ de agar, $23 \mathrm{~g} / \mathrm{L}$ de sacarosa y se ajustó el $\mathrm{pH}$ a 5,7. El medio de cultivo fue dispensado en $10 \mathrm{~mL}$ por frasco y luego se sellaron con papel aluminio y fueron esterilizados en autoclave a 1,2 Bar de presión y una temperatura de $121^{\circ} \mathrm{C}$ durante 20 minutos.

En las tres etapas de evaluación (desinfección e introducción, multiplicación y enraizamiento) los explantes fueron incubados durante 30 días a una temperatura constante de $27^{\circ}$ C, con humedad relativa del $75 \pm 2 \%$ y fotoperiodo de 16 horas luz con intensidad lumínica de 1500 Lux. (Plant Growth Chamber, LGC - 5201 G, LabTech)

\begin{tabular}{|c|c|c|}
\hline Tratamiento & IBA (mg/L) & ANA (mg/L) \\
\hline E1 & 0 & 0 \\
\hline E2 & 1 & 0 \\
\hline E3 & 0 & 1 \\
\hline E4 & 1 & 1 \\
\hline
\end{tabular}

IBA = Ácido Indol Butírico; ANA = Ácido naftalenacético

Tabla 2. Combinación de las auxinas para el enraizamiento in vitro de naranja agria (Citrus aurantium L.).

\section{Diseño experimental, variables medidas y análisis estadístico}

Se empleó un diseño completamente al azar con 10 frascos por tratamiento, cada frasco contenía un explante como unidad experimental y el mismo se repitió tres veces. En la fase de desinfección e introducción se evaluó el porcentaje de contaminación, la oxidación de los explantes y la sobrevivencia, en la fase de multiplicación se evaluó el número de brotes, longitud de los brotes, numero de nudos y numero de hojas por explante y finalmente en la fase de enraizamiento se evaluó el porcentaje de explantes enraizados, longitud de la raíz y número de raíces. Los datos se procesaron mediante Análisis de Varianza (ANVA) con los paquetes estadísticos agricolae y car del programa libre R (versión 4.1.0 para Windows), y la comparación entre las medias se realizó de acuerdo a la prueba de Tukey $(p \leq 0.05)$.

\section{Resultados}

\section{Desinfección y establecimiento in vitro de segmentos nodales}

La evaluación de la desinfección superficial de los segmentos nodales se realizó a los diez días después de realizada la introducción in vitro. La Tabla 3 muestra 0\% de contaminación en los tratamientos T2, T3 y T4. La diferencia entre estos tratamientos se evidenció en el porcentaje de oxidación de los segmentos nodales, obteniéndose $0 \%$ de oxidación en los tratamientos T2 y T3.

\section{Multiplicación in vitro}

La evaluación de los brotes se realizó a los 30 días de cultivo (Figura 1). En la Tabla 4 los resultados indicaron la influencia de combinar dos citoquininas (BAP y KIN) y AG3 en el tratamiento M8 lo que permitió obtener un mayor número de brotes (Figura 2). En el tratamiento M4 se obtuvo un promedio de longitud mayor a los demás tratamientos (Figura 3), mientras que en el promedio de número de nudos los tratamientos M4 y M6 fueron los que no presentaron diferencia significativa, y finalmente para el promedio de número de hojas los tratamientos M3 y M5 fueron los que presentaron los valores más altos, pero no difiriendo significativamente entre ellos.

\section{Enraizamiento in vitro}

La evaluación del enraizamiento se realizó a los 30 días de cultivo (Tabla 5), alcanzado los mejores resultados en el tratamiento E3 compuesto por el medio MS adicionado con 1 $\mathrm{mg} / \mathrm{L}$ de IBA y $1 \mathrm{mg} / \mathrm{L}$ de ANA.

\section{Discusión}

Los tratamientos de desinfección de los segmentos nodales de naranja agria procedentes del invernadero permitieron su establecimiento en condiciones in vitro. Con las concentraciones de 1,5\% (T2) y 2\% (T3) de NaClO se obtuvieron explantes con $0 \%$ de contaminación y oxidación, por lo cual se les considera los mejores tratamientos. La desinfección del material vegetal en la presente investigación se inició con etanol al $70 \%$ y se continuo con soluciones de hipoclorito de sodio, es de gran importancia en la desinfección superficial de los explantes emplear etanol para eliminar contaminantes bacterianos y para los contaminantes fúngicos determinar concentraciones adecuadas de hipoclorito de sodio para no dañar el material vegetal ${ }^{29}$.

\begin{tabular}{|c|c|c|c|c|}
\hline Tratamiento & $\begin{array}{c}\text { NaClO } \\
\mathbf{( \% )}\end{array}$ & $\begin{array}{c}\text { Contaminación } \\
\mathbf{( \% )}\end{array}$ & $\begin{array}{c}\text { Oxidación } \\
\mathbf{( \% )}\end{array}$ & $\begin{array}{c}\text { Sobrevivencia } \\
\mathbf{( \% )}\end{array}$ \\
\hline T1 & 1 & $35 \mathrm{a}$ & $0 \mathrm{~b}$ & $65 \mathrm{~b}$ \\
\hline T2 & 1,5 & $0 \mathrm{~b}$ & $0 \mathrm{~b}$ & $100 \mathrm{a}$ \\
\hline T3 & 2 & $0 \mathrm{~b}$ & $0 \mathrm{~b}$ & $100 \mathrm{a}$ \\
\hline T4 & 2,5 & $0 \mathrm{~b}$ & $52 \mathrm{a}$ & $48 \mathrm{c}$ \\
\hline
\end{tabular}

Medias con letras distintas por columnas difieren significativamente según prueba de Tukey para $\mathrm{p}<0.05$. Tabla 3. Efecto de la concentración de hipoclorito de sodio en la desinfección de los segmentos nodales de naranja agria (Citrus aurantium L.). 


\begin{tabular}{|c|c|c|c|c|}
\hline Tratamiento & $\begin{array}{l}\text { Promedio de } \\
\mathrm{N}^{\circ} \text { de brotes } \\
\text { por explante }\end{array}$ & $\begin{array}{l}\text { Promedio de } \\
\text { longitud de } \\
\text { brotes }(\mathrm{mm})\end{array}$ & $\begin{array}{c}\text { Promedio de } \mathrm{N}^{\circ} \\
\text { de nudos por } \\
\text { explante }\end{array}$ & $\begin{array}{c}\text { Promedio de } \mathrm{N}^{\circ} \\
\text { de hojas por } \\
\text { explante }\end{array}$ \\
\hline M1 & $1,3 \mathrm{~d}$ & $17,7 \mathrm{~d}$ & $1,2 \mathrm{~d}$ & $5,4 \mathrm{~b}$ \\
\hline M2 & $3,3 \mathrm{~b}$ & $27,6 \mathrm{c}$ & $1,6 \mathrm{~d}$ & $5,7 \mathrm{~b}$ \\
\hline M3 & $2 \mathrm{c}$ & $37,4 \mathrm{~b}$ & $3,4 \mathrm{~b}$ & $6,5 \mathrm{a}$ \\
\hline M4 & $1,6 \mathrm{~cd}$ & $46,6 \mathrm{a}$ & $4,5 \mathrm{a}$ & $5,6 \mathrm{~b}$ \\
\hline M5 & $2,2 \mathrm{c}$ & $33,1 \mathrm{~b}$ & $3,2 \mathrm{~b}$ & $6,2 \mathrm{a}$ \\
\hline M6 & $2,4 \mathrm{c}$ & $30,4 \mathrm{bc}$ & $4,3 \mathrm{a}$ & $3,8 \mathrm{~d}$ \\
\hline M7 & $1 \mathrm{~d}$ & $36,8 \mathrm{~b}$ & $3,1 \mathrm{~b}$ & $5,2 \mathrm{c}$ \\
\hline M8 & $4,7 \mathrm{a}$ & $29,4 \mathrm{bc}$ & $2,3 \mathrm{c}$ & $4,1 \mathrm{~d}$ \\
\hline
\end{tabular}

Tabla 4. Efecto de los reguladores de crecimiento en el establecimiento in vitro de naranja agria (Citrus aurantium L.).

Medias con letras distintas por columnas difieren significativamente según prueba de Tukey para $\mathrm{p}<0.05$.

\begin{tabular}{|c|c|c|c|}
\hline Tratamiento & $\begin{array}{c}\text { Explantes } \\
\text { enraizados (\%) }\end{array}$ & $\begin{array}{c}\text { Promedio de } \\
\text { longitud de raíces } \\
\mathbf{( m m})\end{array}$ & $\begin{array}{c}\text { Promedio de } \mathbf{N}^{\circ} \text { de } \\
\text { raíces por explante }\end{array}$ \\
\hline E1 & $0 \mathrm{~d}$ & $0 \mathrm{c}$ & $0 \mathrm{c}$ \\
\hline E2 & $22,3 \mathrm{c}$ & $26,6 \mathrm{a}$ & $1,3 \mathrm{~b}$ \\
\hline $\mathbf{E 3}$ & $66,8 \mathrm{~b}$ & $13,7 \mathrm{~b}$ & $1,2 \mathrm{~b}$ \\
\hline $\mathbf{E 4}$ & $94,7 \mathrm{a}$ & $23,4 \mathrm{a}$ & $2,2 \mathrm{a}$ \\
\hline
\end{tabular}

Medias con letras distintas por columnas difieren significativamente según prueba de Tukey para $\mathrm{p}<0.05$.

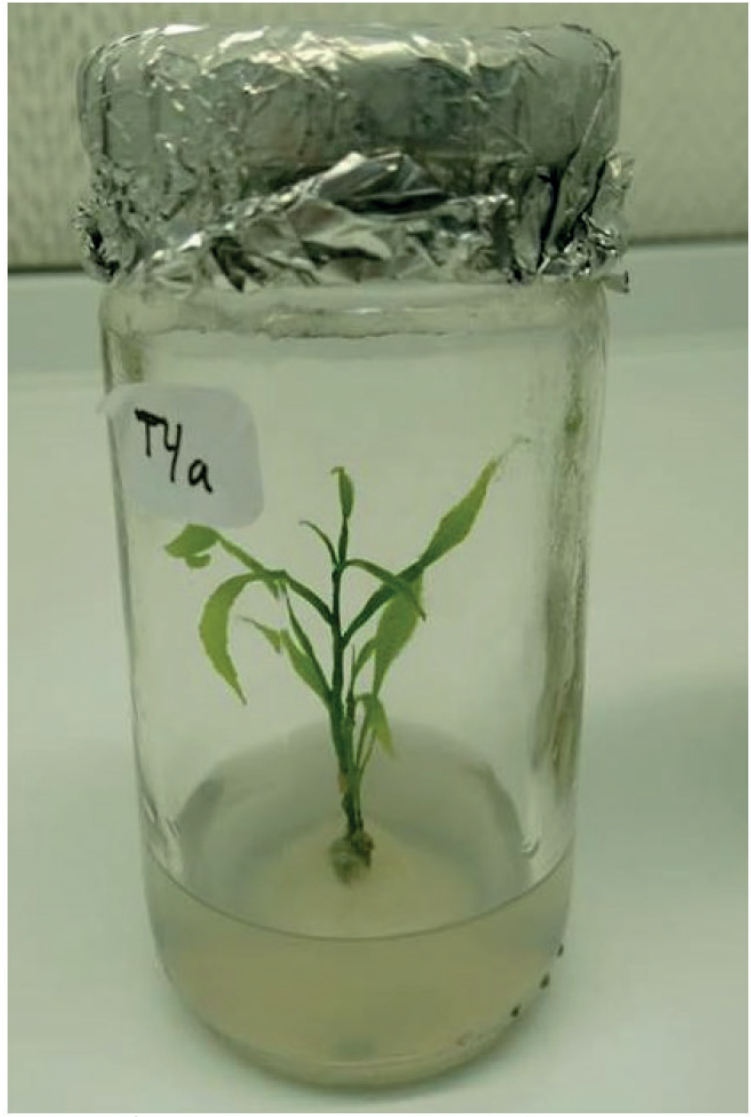

Figura 1. Plántulas in vitro de naranja agria (Citrus aurantium L.) a los 30 días de cultivo en la etapa de multiplicación.
En la fase de desinfección y establecimiento in vitro, los tratamientos utilizados en la presente investigación presentan mejores resultados en comparación de otros autores que han trabajo con especies del mismo género, como (25), que utilizó hipoclorito de sodio al 0,6\% durante 15 minutos para la desinfección de segmentos nodales de Citrus aurantiifolia, logrando un porcentaje de contaminación del 56\%. Mientras que (23), lograron porcentajes de contaminación del 0\% al emplear hipoclorito de sodio al 1\% durante 20 minutos, pero además los autores utilizaron un segundo lavado transcurrida las 24 horas y adicionalmente los sumergió por una solución de sulfato de cobre al $2 \%$ en la desinfección de yemas apicales de Citrus limon.

En la multiplicación in vitro de los segmentos nodales de naranja agria el tratamiento con medio de cultivo MS suplementado con 0,25 mg/L KIN, 0,25 mg/L BAP y 0,25 mg/L AG3 permitió obtener el mayor número de brotes con 4,7 brotes por explante. Este resultado está en relación a la adición de los tres reguladores de crecimiento, mientras que en los demás tratamientos que se adicionaron dos reguladores de crecimiento se vieron significativamente afectados en la disminución del número de brotes por explante en comparación a los tratamientos donde solo se adiciono un regulador de crecimiento, coincidiendo con (26), quienes obtuvieron una disminución en la formación de brotes de citrumelo (Poncirus trifoliata (L.) Raf. $\times$ Citrus paradisi McFaden) con tratamientos adicionando BAP y KIN, en comparación donde solo utilizaron BAP. Resultados similares obtuvo (25) quien no encontró diferencia significativa en el uso de BAP asociado con KIN que al utilizar únicamente BAP. Mientras que (27) emplearon un medio de cultivo MS suplementado con $2 \mathrm{mg} / \mathrm{L}$ de BAP y 0,6 mg/L de AG3 para la formación de brotes de naranja agria, donde obtuvieron dos 


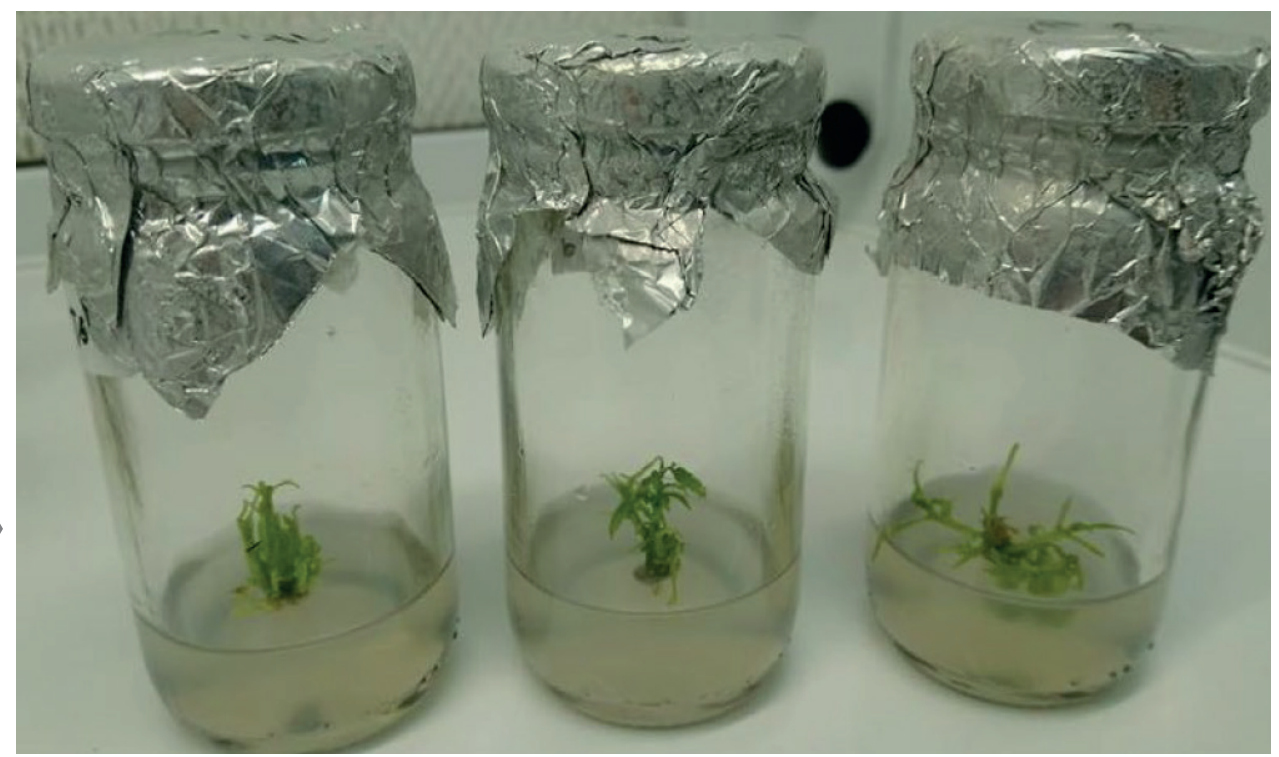

Figura 2. Efecto de la combinación de BAP, KIN y AG3 en el cultivo in vitro de naranja agria (Citrus aurantium L.), a los 30 días de cultivo.

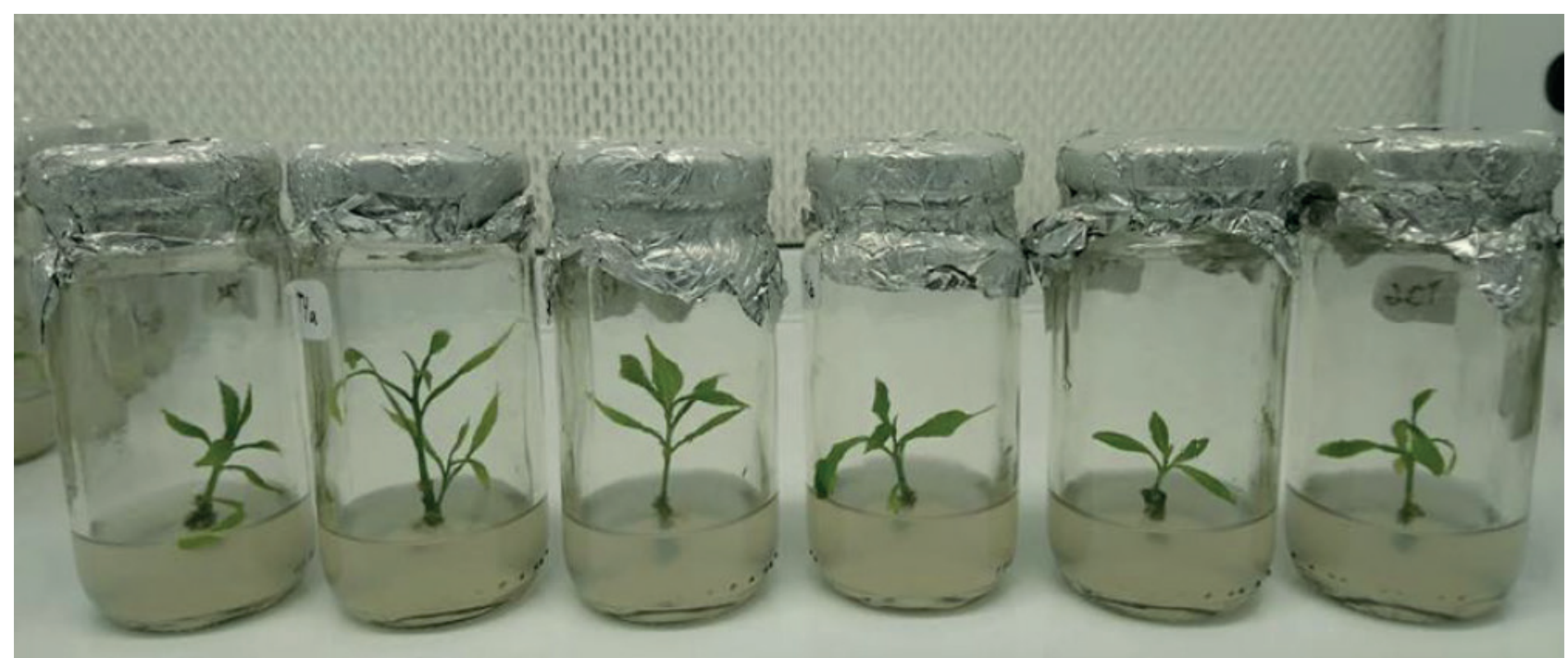

Figura 3. Efecto del AG3 en el cultivo in vitro de naranja agria (Citrus aurantium L.), a los 30 días de cultivo.

brotes por segmento nodal, resultado muy cercano al obtenido con el tratamiento M6 en la presente investigación.

El tratamiento M4 fue el que presento mayor longitud de los brotes con $46.6 \mathrm{~mm}$, esto es debido a que este medio de cultivo solo estaba suplementado con AG3. (30) señalan que en Citrus se utiliza generalmente AG3 para aumentar la longitud de los brotes. Pero al adicionar AG a los demás tratamientos con BAP y KIN no tuvo mayor efecto en la longitud de los brotes que en los tratamientos donde solo se adicionó una de las citoquininas. Estos resultados guardan relación con estudios realizados en evaluación del uso de BAP en adición con AG3 en Citrus aurantium ${ }^{27}$ y Citrus limon ${ }^{31}$, donde concluyeron que no había diferencia significativa en comparación con los resultados obtenidos con los tratamientos donde solo se adicionó BAP en el medio de cultivo.

El mayor número de hojas se logró obtener con el medio de cultivo MS suplementado con $0,25 \mathrm{mg} / \mathrm{L}$ de $\mathrm{KIN}$, con un promedio de 6,5 hojas por explante. Este resultado coincide con (23), quienes obtuvieron 6 hojas en promedio por brote al utilizar el medio MS adicionado con 0,25 mg/L de KIN. Además, se observaron hojas atrofiadas en los tratamientos con mayor número de brotes y combinación de reguladores de crecimiento, similar a lo obtenido por (27), que al utilizar el medio de cultivo con $2 \mathrm{mg} / \mathrm{L}$ de BAP combinado con $1 \mathrm{mg} / \mathrm{L}$ AG3 dieron lugar a nuevos explantes atrofiados con hojas estrechas e hiperhidricidad de naranja agria.

En la fase de enraizamiento el tratamiento E4 con medio MS al cual se le adicionó $1 \mathrm{mg} / \mathrm{L}$ de IBA y $1 \mathrm{mg} / \mathrm{L}$ de ANA fue el que presentó mejores resultados, obtenido 94,7 \% de explantes con raíces. Estos resultados reafirman los logrados por (32), quienes comprobaron que ANA induce porcentajes más altos de enraizamiento que IBA en varias especies del género Citrus. Además, los resultados de nuestro trabajo son similares a los obtenidos por (27) en naranja agria, con casi 95\% de explantes enraizados cuando combinaron en el medio de cultivo $1 \mathrm{mg} / \mathrm{L}$ de IBA con 1 o $2 \mathrm{mg} / \mathrm{L}$ de ANA.

Con lo demostrado se puede regenerar plantas de naranja agria a partir de segmentos nodales en condiciones in vitro, de esta manera al tener mayor número de brotes por explante permitirá del mismo modo obtener una mayor tasa de multiplicación. Además de que se logra porcentajes de enraizamiento mayor al 94\%, lo cual asegura que las plantas puedan desarrollarse adecuadamente. Con las plantas producidas por este método se pretende recuperar y repoblar la campiña de Huacho al ser una especie de gran importancia en la gastronomía local. Finalmente, también se podrá emplear el germoplasma en condiciones in vitro para programas de mejoramiento genético vegetal. 


\section{Conclusiones}

Se logró micropropagar in vitro naranja agria a partir de segmentos nodales. Los mejores resultados en la fase de desinfección en los explantes se obtuvieron al emplear 1,5\% y $2 \%$ de hipoclorito de sodio. En la fase de la multiplicación in vitro los mejores resultados se obtuvieron en el medio de cultivo con $0,25 \mathrm{mg} / \mathrm{L}$ de BAP, 0,25 mg/L KIN y 0,25 mg/L de AG3, el cual se recomienda emplear por permitir obtener mayor número de brotes. Y finalmente en la fase de enraizamiento el medio suplementado con $1 \mathrm{mg} / \mathrm{L}$ de IBA y $1 \mathrm{mg} / \mathrm{L}$ de ANA permitió obtener el mayor porcentaje de explantes enraizados y número de raíces.

\section{Referencias bibliográficas}

1. Schimmenti E, Borsellino V, Galati A. Growth of citrus production among the Euro-Mediterranean countries: political implications and empirical findings. Spanish Journal of Agricultural Research 2013, 11(3): 561-577.

2. Fatih $\mathrm{H}$, Söyler $\mathrm{O}$. Citrus production and evaluation of export in the World and Turkey. The Journal of Academic Social Sciences 2018, 79:357-366.

3. FAO. 2017. Citrus Fruit - Fresh and Processed. Statistical Bulletin 2016. Rome. http://www.fao.org/economic/est/est-commodities/ citricos/es/

4. Márquez O, Cosio R, Márquez F, Robladillo L. Production and export of peruvian mandarin to the russian federation market, as a business opportunity, period 2013-2017. Journal of Global Management Sciences 2018, 1(1): 22-29.

5. Acosta-Pérez J, Ortiz-García C, Zaldívar-Cruz J, Rodríguez-Cuevas M, Bautista-Muñoz M, Castillo-Aguilar C. Identificación del agente causal e importancia de la gomosis en la zona citricola de Huimanguillo, Tabasco, México. Universidad y Ciencia 2012, 28(3): 245-258.

6. Díaz H, Honorio Z, Hernández A, Durand M, Gózalo A, Domínguez G. Identificación de especies frutícolas nativas con potencialidad productiva en peligro de extinción en la provincia de Huaura. Aporte Santiaguino 2020, 13(2): 78-91.

7. Díaz-Pillasca HB, Hernández-Amasifuen AD, Machahua M, Pineda-Lázaro AJ, Argüelles-Curaca A, Lugo B. DNA barcoding of three species of fruit trees with economic potential from the $\mathrm{Hu}-$ aura Valley, Lima, Peru. Revista Bionatura 2021, 6(3): 1992-2000.

8. Murcia R, Osorio A, Caicedo A, Calvert L, Morales F. Distribución y Caracterización Serológicas de Aislamiento del Virus de la Tristeza de los Cítricos en Colombia. Fitopatología Colombiana 2002, 26(1): 21-26.

9. Quiroga J, Hernandez F, Silva M, Orduz J. Comportamiento de la producción de lima Tahití (Citrus latifolia Tanaka), injertada sobre el patrón de mandarina Cleopatra (Citrus reticulata Blanco) y la influencia del virus de la tristeza (CTV) en condiciones del piedemonte del Meta, 1997-2008. Orinoquia 2010, 14(1): 5-15.

10. Martínez-Hernández M, Alonso A, Osorio-Acosta F, Gallardo F, López H, Mata M. Cultivo in vitro de patrones de cítricos tolerantes al virus de la tristeza, empleando sustratos inertes alternativos al agar. Interciencia 2006, 31(8): 616-619.

11. Chaparro-Zambrano N, Velásquez H, Orduz-Rodríguez J. Influencia del virus de la tristeza de los cítricos (CTV) en el comportamiento de la lima ácida Tahití (Citrus latifolia Tanaka) injertada sobre seis patrones en el piedemonte llanero de Colombia (1997 - 2008). Ciencia \& Tecnología Agropecuaria 2013, 14(1): 33-38.

12. Cervera F, Fagoaga M, Durán-Vila C, Peña N. Applications of biotechnology to citrus improvement in spain. Acta Horticult. 2004, 632(1): 221-234.

13. Hasan M, Hasan M, Foysal S, Hoque H, Khan M, Bhuiyan M, Prodhan S. In-Vitro Regeneration of Citrus sinensis (L.) Osbeck from Mature Seed Derived Embryogenic Callus on Different Solid Basal Media. American Journal of Plant Sciences 2019, 10(2): 285-297.
14. Pineda A, Hernández A, Díaz H. Multiplicación y reducción del crecimiento in vitro de papa chaucha (Solanum tuberosum L. grupo Phureja). Manglar 2021, 18(2): 42-47.

15. González J, Zawadski K. Aplicación de la biotecnología en cítricos para el desarrollo de plantas libres de patógenos en Paraguay. Revista de Ciencia y Tecnología 2019, 31(1): 16-21.

16. Khan M, Hoque H, Islam M, Ashrafuzzaman M, Prodhan S. An Efficient Regeneration System for Native Orange (Citrus reticulata) through In-Vitro Culture Technique. Agricultural Sciences 2019, 10(7): 975-984.

17. Hernández A, Pineda A, Rojas J, Díaz H. Regeneración in vitro de arnaucho (Capsicum chinense Jacq.) a partir de yemas apicales. Manglar 2021, 18(1): 71-75.

18. Jardak R, Boubakri H, Zemni H, Gandoura S, Mejri S, Mliki A, Ghorbel A. Establishment of an in vitro regeneration system and genetic transformation of the Tunisian 'Maltese half-blood' (Citrus sinensis): an agro-economically important variety. 3 Biotech 2020, 10: 99.

19. Haradzi N, Khor P, Subramaniam S, Chew B. Regeneration and micropropagation of Meyer lemon (Citrus $\mathrm{x}$ meyeri) supported by polymorphism analysis via molecular markers. Scientia Horticulturae 2021, 286(10):11022.

20. Kobayashi A, Bespalhok J, Pereira L, Vieira L. Plant regeneration of sweet orange (Citrus sinensis) from thin sections of mature stem segments. Plant Cell Tissue and Organ Culture 2003, 74(1): 99-102.

21. Hernández Y, Silva J, y Borges M. Establecimiento y multiplicación in vitro de Citrus aurantifolia Christm. Swing. var. 'Mexicana' a partir de semillas. Biotecnología Vegetal 2013, 13(3): 181 $-187$.

22. Llihua L, Calderón A, Cabrera R. Influencia de sacarosa y cotiledones en la microinjertación de cítricos. Revista Científica Ecuatoriana 2019, 6(1): 24-35.

23. Chávez J, Arboleda M. Propagación in vitro del limón criollo (Citrus limon) con el empleo de dos reguladores de crecimiento. Tesis de Pregrado. Universidad Técnica de Cotopaxi. Ecuador. 2011

24. Pérez-Tornero O, Tallón C, Porras I. An efficient protocol for micropropagation of lemon from mature nodal segments. Plant Cell Tissue and Organ Culture 2009, 100(3): 263-271.

25. Vidal M. Propagación in vitro de lima ácida (Citrus aurantiifolia [Christm.] Swingle)-variedad Tahití-a partir de segmentos nodales. Tesis de Pregrado. Escuela Agrícola Panamericana, Zamorano, Honduras. 2014.

26. Sen S, Dhawan V. Development of a Highly Efficient Micropropagation Method for the Citrus Rootstock 'Swingle' Citrumelo [Poncirus trifoliata (L.) Raf. $\times$ C. paradisi McFaden]. International Journal of Fruit Science 2010, 10(1): 65-78.

27. Tallón C, Porras I, Pérez-Tornero O. Efficient propagation and rooting of citrus rootstocks using different plant growth regulators. In vitro Cell. Dev. Biol-Plant 2012, 48(5): 488-499.

28. Murashige T, Skoog F. 1962. A revised medium for rapid growth and bioassays with tobacco tissue culture. Physiologia Plantarum 1962, 15(3): 473-497.

29. Azofeifa A. Problemas de oxidación y oscurecimiento de explantes in vitro. Agronomía mesoamericana 2009, 20(1): 153-175.

30.Carimi F, De Pasquale F. Micropropagation of Citrus. In: Jain SM, Ishii K (eds) micropropagation of woody trees and fruits. Forestry Sciences 2003, vol 75. Springer, Dordrecht pp 589-619.

31. Kotsias D, Roussos P. An investigation on the effect of different plant growth regulating compounds in in vitro shoot tip and node culture of lemon seedlings. Scientia Horticulturae 2001, 89(2):115-128.

32. Rathore J, Rathore M, Singh M, Singh R, Shekhawat N. Micropropagation of mature tree of Citrus limon. Indian Journal of Biotechnology 2007, 6(2): 239-244.

Received: 11 junio 2021

Accepted: 29 septiembre2021 